\title{
Analisis Kestabilan Model Interaksi Dua Pemangsa-Satu Mangsa Dengan Daya Dukung Lingkungan Pada Sistem Mangsa
}

\author{
${ }^{1}$ Yohanes A. R. Langi \\ ${ }^{(1)}$ Program Studi Matematika, FMIPA, UNSRAT, yarlangi@gmail.com
}

\begin{abstract}
Abstrak
Interaction on every living in this world have positive effect, negative. Effect, and also have no effect to other living things. This paper would talk about interaction model between two predators-one prey with environmental support to predator system which based on Lotka-Volterra model. Model arranged by variable $R$ (number of predators), $H$ (number of main predators), $C$ (number of predators which commensalisms to $H$ ), $u$ (predators grow up level $R$ ), $\mathrm{v}$ (predatorily level $C), w$ (predatorily level $H$ ), $\theta$ (conversion efficiently $C), \rho$ (conversion efficiently $H$ ), $x$ (predator's deadly level $C$ ), $y$ (predator's deadly level $H), z$ (commensalisms relation between predators $C$ with predator $H),\left(1-\frac{N}{K}\right)$ (environmental support which could contain predator's grow). Research's result give stability point at fixed point which there is only main predator $(H)$ and prey in using the environmental support will reduce as big as main predatorily level to prey $\left(T_{2 .}\right)$. Stability point also happen on fixed point where there only prey in using environmental support which will reduce as big as predatorily level to prey $\left(\left(T_{3}\right)\right.$.
\end{abstract}

Keywords : Predator-pray, Stability, Differential Equation

\begin{abstract}
Abstrak
Interaksi antar makhluk hidup dalam kehidupan ini ada yang berdampak positif,negative, dan ada pulah ynag tidak berpengaruh terhadap mahkluk hidup lain. Tulisan ini akan membahas model interaksi antara dua pemangsa-satu mangsa dengan daya dukung lingkungan pada system mangsa yang di dasari dari model lotka - Volterra .Pada model yang dikembangkan diasumsikan bahwa interaksi antar pemangsa bersifat komensalis.Model model yang disusun disini terdiri atas varibel-variabel R (banyaknya mangsa), H (banyaknya mangsa inang), C (banyaknya pemangsa yang komensalis terhadap $\mathrm{H}$ ), u (tingkat pertumbuhan mangsa R), v (tingkat pemangsaan pemangsa $\mathrm{C}$ ), w (tingkat pe mangsaan pemangsa $\mathrm{H}$ ), $\theta$ (efisiensi konversi C), $\rho$ (efisiensi konversi $\mathrm{H}$ ), $\mathrm{x}$ (tingkat kematian pemangsa $\mathrm{C}$ ), y (tingkat kematian pemangsa $\mathrm{H}$ ), $\mathrm{z}$ (hubungan komensalisme antara pemangsa $\mathrm{C}$ dan pemangsa $\mathrm{H}$ ), $\left(1-\frac{N}{K}\right)$ (daya dukung lingkungan yang masih dapat menampung pertumbuhan mangsa). Dari hasil penelitian diperoleh titik kestabilan pada titik tetap dimana hanya terdapat pemangsa inang $(\mathrm{H})$ dan mangsa dalam menggunakan daya dukung lingkungan yang ada akan berkurang sebesar tingkat pemangsaan pemangsa inang terhadap mangsa $\left(\mathrm{T}_{2}\right)$. Titik kesatabilan juga terjadi pada titik tetap dimana hanya terdapat mangsa dalam menggunakan daya dukung lingkungan yang ada akan berkurang sebesar tingkat pemangsa inang terhadap mangsa( $\left.\mathrm{T}_{3}\right)$.
\end{abstract}

Kata Kunci : Mangsa-Pemangsa, Kestabilan, Persamaan Difrensial

\section{Pendahuluan}

Secara umum, jenis-jenis interaksi dapat digolongkan menjadi dua yaitu interaksi negatif dan interaksi positif. Dalam kehidupan umumnya terdiri lebih dari dua spesies yang saling berinteraksi, dan tak jarang terjadinya persaingan untuk mempertahankan hidup mengingat terbatasnya daya dukung lingkungan, dimana daya dukung itu berupa makanan, habitat, tata ruang dan lain-lain [15].

Dalam penelitian ini akan dibahas suatu interaksi tiga spesies yang terdiri dari dua pemangsa dan satu mangsa dimana dalam sistem mangsa diakomodasikan daya dukung lingkungan. Interaksi antar kedua pemangsa ini bersifat komensalisme yaitu, salah satu spesies diuntungkan sedangkan spesies yang lain tidak. Interaksi mangsa dan pemangsa dengan daya dukung lingkungan pada sistem mangsa mengikuti model Lotka-Volterra. Tujuan Penelitian untuk menentukan kestabilan disekitar titik tetap pada model dua pemangsa dan satu mangsa dengan mengakomodasikan daya dukung lingkungan pada sistem mangsa. 


\section{Model, Analisa, Desain dan Implementasi}

\subsection{Sistem Persamaan Diferensial}

Misalkan $a$ dan $b$ fungsi-fungsi dalam $t$ yang kontinu pada suatu selang tertentu. Persamaan linier orde satu berbentuk :

$$
\frac{d x}{d t}+a(t) x=b(t)
$$

Khususnya jika $b(t)=0$ maka persamaan diferensial (1) disebut persamaan diferensial linier homogen orde satu.

Selanjutnya, pandang sistem persamaan diferensial berikut :

$$
\begin{aligned}
& \frac{\mathrm{dX}}{\mathrm{dt}}=f(X), \quad X \in \mathfrak{R}^{n} \\
& \frac{d X}{d t}=A X
\end{aligned}
$$

Persamaan (3) disebut sistem linier [14].

Berikut ini akan ditentukan solusi dari sistem persamaan diferensial (3)

Misalkan pada persamaan (3), $A$ adalah matriks berukuran $n x n$, dan $\lambda_{1}, \lambda_{2}, \ldots ., \lambda_{n}$ adalah nilai-nilai eigen $A$ yang bernilai rill dan berbeda, serta vektor eigen $v_{1}, v_{2}, \ldots, v_{n}$ yang bebas linier. Maka solusi umum persamaan diferensial (3) adalah

$X(t)=c_{1} v_{1} e^{\lambda_{1} t}+c_{2} v_{2} e^{\lambda_{2} t}+\ldots+c_{n} v_{n} e^{\lambda_{n} t}$

Dengan $c 1, c 2, \ldots c n$ adalah kostanta sembarang.

Jika semua bagian rill dari nilai eigen $A$ negatif, maka untuk $t \rightarrow \infty$,

$X(t)$ mendekati nol. Dengan kata lain, titik tetap dari sistem persamaan diferensial (3) dikatakan stabil, jika semua bagian rill dari nilai eigen matriks $A$ adalah negatif [1].

\subsection{Pelinearan}

Lihat persamaan diferensial tak linier berikut :

$$
\begin{aligned}
& \frac{d x}{d t}=P(x, y, z) \\
& \frac{d y}{d t}=Q(x, y, z) . \\
& \frac{d z}{d t}=S(x, y, z)
\end{aligned}
$$

dengan turunan parsial dari fungsi P, Q, S kontinu di $\mathfrak{R}^{3}[9]$.

Berikut ini akan dilakukan pelinearan terhadap sistem persamaan diferensial (5). Untuk itu, perhatikan uraian Taylor di sekitar titik $X^{*}=\left(x^{*}, y^{*}, z^{*}\right)$ berikut :

$$
\begin{aligned}
& P(x, y, z)=P\left(x^{*}, y^{*}, z^{*}\right)+\frac{\partial P\left(x^{*}, y^{*}, z^{*}\right)}{\partial x}\left(x-x^{*}\right)+\frac{\partial P\left(x^{*}, y^{*}, z^{*}\right)}{\partial y}\left(y-y^{*}\right)+\frac{\partial P\left(x^{*}, y^{*}, z^{*}\right)}{\partial z}\left(z-x^{*}\right)+\eta_{I}(x, y, z) \\
& Q(x, y, z)=Q\left(x^{*}, y^{*}, z^{*}\right)+\frac{\partial Q\left(x^{*}, y^{*}, z^{*}\right)}{\partial x}\left(x-x^{*}\right)+\frac{\partial Q\left(x^{*}, y^{*}, z^{*}\right)}{\partial y}\left(y-y^{*}\right)+\frac{\partial Q\left(x^{*}, y^{*}, z^{*}\right)}{\partial z}\left(z-z^{*}\right)+\eta_{1}(x, y, z) \\
& S(x, y, z)=S\left(x^{*}, y^{*}, z^{*}\right)+\frac{\partial S\left(x^{*}, y^{*}, z^{*}\right)}{\partial x}\left(x-x^{*}\right)+\frac{\partial S\left(x^{*}, y^{*}, z^{*}\right)}{\partial y}\left(y-y^{*}\right)+\frac{\partial S\left(x^{*}, y^{*}, z^{*}\right)}{\partial z}\left(z-z^{*}\right)+\eta_{I}(x, y, z)
\end{aligned}
$$

Untuk $i=1,2,3$ sementara itu 
Dengan demikian sistem persamaan diferensial (6) dapat direduksi menjadi

$$
\begin{aligned}
& \frac{\mathrm{d}}{\mathrm{dt}}\left[\begin{array}{l}
\mathrm{x}-\mathrm{x} * \\
\mathrm{y}-\mathrm{y}^{*} \\
\mathrm{z}-\mathrm{z}^{*}
\end{array}\right]=\left[\begin{array}{lll}
\frac{\partial P\left(x^{*}, y^{*}, z^{*}\right)}{\partial x} & \frac{\partial P\left(x^{*}, y^{*}, z^{*}\right)}{\partial y} & \frac{\partial P\left(x^{*}, y^{*}, z^{*}\right)}{\partial z} \\
\frac{\partial Q\left(x^{*}, y^{*}, z^{*}\right)}{\partial x} & \frac{\partial Q\left(x^{*}, y^{*}, z^{*}\right)}{\partial y} & \frac{\partial Q\left(x^{*}, y^{*}, z^{*}\right)}{\partial z} \\
\frac{\partial S\left(x^{*}, y^{*}, z^{*}\right)}{\partial x} & \frac{\partial S\left(x^{*}, y^{*}, z^{*}\right)}{\partial y} & \frac{\partial S\left(x^{*}, y^{*}, z^{*}\right)}{\partial z}
\end{array}\right]\left[\begin{array}{c}
x-x^{*} \\
y-y^{*} \\
z-z^{*}
\end{array}\right] \\
& +\left[\begin{array}{l}
\eta_{1}(x, y, z) \\
\eta_{2}(x, y, z) \\
\eta_{3}(x, y, z)
\end{array}\right]
\end{aligned}
$$

\subsection{Inte raksi Multispesies dan Krite ria Kestabilan Routh-Hurwitz}

Sistem interaksi multispesies dimodelkan dengan penyusunan persamaan simultan $k$ spesies, berikut :

Atau dalam notasi vektor berbentuk:

$$
\frac{d N}{d t}=F(N)
$$

Berikut ini akan diberikan suatu kondisi yang membuat titik tetap dari sistem (7) stabil.

$$
J=\frac{\partial F}{\partial N}\left(N^{*}\right)=\left[\begin{array}{ccc}
\frac{\partial f_{l}}{\partial N_{l}} & \cdots & \frac{\partial f_{k}}{\partial N_{k}} \\
\vdots & \ddots & \vdots \\
\frac{\partial f_{k}}{\partial N_{l}} & \cdots & \frac{\partial f_{k}}{\partial N_{k}}
\end{array}\right]_{N^{*}}
$$

Matriks Jacobi $\mathrm{J}$ berukuran $k x k$ ini disebut juga matriks komunitas. Matriks Jacobi tersebut merupakan matriks interaksi sistem dengan $k$-spesies yang akan digunakan untuk menguji apakah disuatu titik tetap yang diperoleh bersifat stabil atau tidak [14].

\section{Teorema 1. (Routh-Hurwitz Condition)}

Misalkan $a_{1}, a_{2}, \ldots . a_{k}$ bilangan-bilangan rill, $a j=0$ jika $j>k$. Semua nilai eigen dari persamaan karakteristik.

$$
P(\lambda)=\lambda^{k}+a_{1} \lambda^{k-1}+\cdots+a_{k-2} \lambda^{2}+a_{k-1} \lambda+a_{k}=0
$$

Mempunyai bagian rill yang negatif jika dan hanya jika untuk setiap $i=1,2,3, \ldots, k$ determinan dari matriks ixi, adalah positif [6].

Sehingga menurut kondisi Routh-Hurwitz dalam teorema 1, untuk suatu $k$ disebutkan bahwa titik tetap $N^{*}$ stabil jika dan hanya jika (untuk k $=1,2,3,4$ ),

$$
\begin{array}{ll}
k=1 & a 1>0 \\
k=2 & a 1>0, a 2>0 \\
k=3 & a 1>0, a 3>0, a 1 a 2>a 3 \\
k=4 & a 1>0, a 3>0, a 4>0, a 1 a 2 a 3>a_{3}^{2}+a_{1}^{2} a_{4} .
\end{array}
$$

Jika salah satu kondisi tidak terpenuhi maka sistem tidak stabil. 


\subsection{Model Logistik}

Model umum laju pertumbuhan logistic, [8]:

$$
\frac{d N}{d t}=r N
$$

\subsection{Model Interaksi Dua Pemangsa-Satu Mangsa dengan Daya dukung pada Sistem Mangsa}

Misalkan $N$ adalah banyaknya mangsa pada waktu $t, P$ banyaknya pemangsa pada waktu $t$. $K$ adalah daya dukung lingkungan pada sistem mangsa. Maka setiap penambahan mangsa $(N)$ akan menyebabkan daya dukung berkurang $(K-N)$ dan jika setiap kebutuhan yang masih dapat menampung pertumbuhan mangsa $\left(\frac{\mathrm{K}-\mathrm{N}}{\mathrm{K}}\right)=1-\frac{\mathrm{N}}{\mathrm{K}}$, maka laju pertumbuhan intrinsik mangsa $(r)$ terhadap proporsi kebutuhan yang masih dapat menampung pertumbuhan mangsa adalah $r$ $\left(1-\frac{\mathrm{N}}{\mathrm{K}}\right)$ dikurangi sejumlah pengurangan laju pertumbuhan populasi mangsa akibat interaksi dengan pemangsa $(a P)$.

Sehingga model mangsa-pemangsa Lotka-Volterra dapat dinyatakan dalam bentuk:

$$
\begin{array}{ll}
\frac{\mathrm{dN}}{\mathrm{Ndt}}=\mathrm{r}\left(1-\frac{\mathrm{N}}{\mathrm{K}}\right)-\mathrm{aP} & \Leftrightarrow \frac{\mathrm{dN}}{\mathrm{dt}}=\mathrm{N}\left(\mathrm{r}\left(1-\frac{\mathrm{N}}{\mathrm{K}}\right)-\mathrm{aP}\right) \\
\frac{\mathrm{dP}}{\mathrm{Pdt}}=\mathrm{bN}-\mathrm{c} & \Leftrightarrow \frac{\mathrm{dP}}{\mathrm{dt}}=\mathrm{P}(\mathrm{bN}-\mathrm{c})
\end{array}
$$

dengan

$a$ = variabel yang berhubungan dengan efis iensi pemangsaan pemangsa.

$b=$ variabel yang menyatakan efisiensi interaksi mangsa (sebagai makanan) oleh pemangsa.

Untuk masalah multispesies, dalam hal ini 3 spesies yaitu dua pemangsa dan satu mangsa dengan daya dukung lingkungan pada sistem mangsa, model diatas dapat diperluas menjadi :

$$
\begin{aligned}
& \frac{d N}{d t}=N\left(r\left(1-\frac{N}{K}\right)-a_{1} p_{1}-a_{2} p_{2}\right) \\
& \frac{d P_{1}}{d t}=P_{1}\left(b_{1} N-c_{1}\right) \\
& \frac{d P_{2}}{d t}=P_{2}\left(b_{2} N-c_{2}\right)
\end{aligned}
$$

Dengan penulisan ulang model interaksi dua pemangsa-satu mangsa dengan daya dukung lingkungan dapat dinyatakan dalam bentuk :

$$
\begin{aligned}
\frac{\mathrm{dR}}{\mathrm{dt}} & =\mathrm{R}\left(\mathrm{u}\left(1-\frac{\mathrm{R}}{\mathrm{K}}\right)-\mathrm{vC}-\mathrm{wH}\right) \\
\frac{\mathrm{dC}}{\mathrm{dt}} & =\mathrm{C}(\theta v \mathrm{R}+\mathrm{Hz}-\mathrm{x}) \\
\frac{\mathrm{dH}}{\mathrm{dt}} & =\mathrm{H}(\rho w \mathrm{R}-\mathrm{y})
\end{aligned}
$$

Dengan

$R \quad=$ Banyaknya Mangsa

$H \quad=$ Banyaknya pemangsa Inang

$C \quad=$ Banyaknya pemangsa yang komensalis terhadap $H$ 


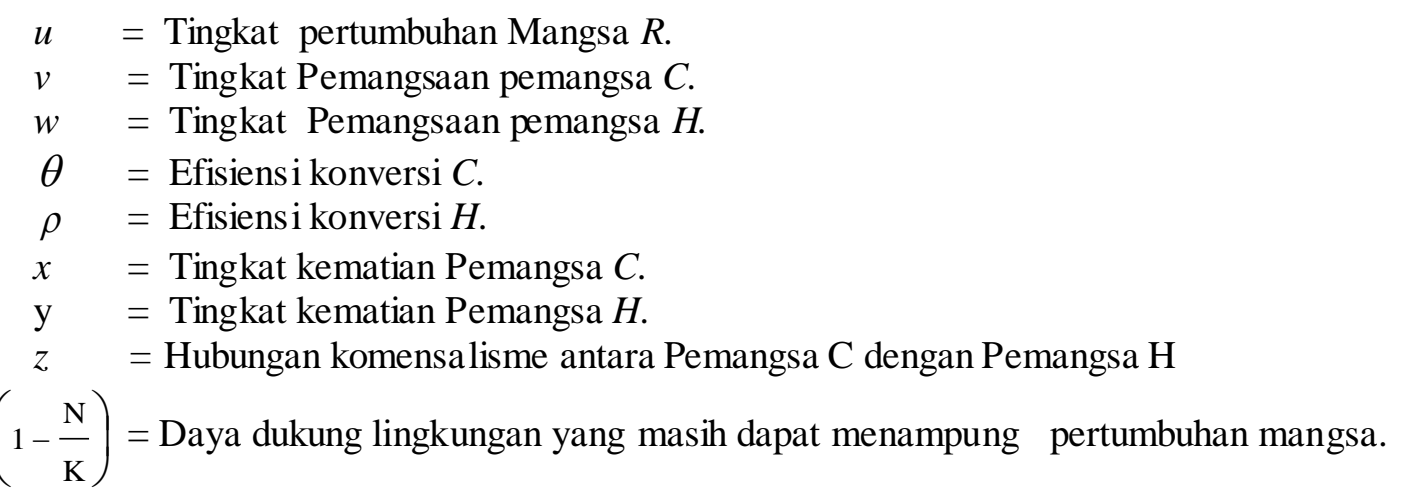

$R, C, H \geq 0$ dan $v, w, \rho, \theta, x, y, K, z>0$

\section{Hasil dan Pembahasan}

\subsection{Penentuan titik tetap}

Perhatikan persamaan persamaan (2.16)-(2.18):

$$
\begin{aligned}
\frac{\mathrm{dR}}{\mathrm{dt}} & =\mathrm{R}\left(\mathrm{u}\left(1-\frac{\mathrm{R}}{\mathrm{K}}\right)-\mathrm{vC}-\mathrm{wH}\right) \\
\frac{\mathrm{dC}}{\mathrm{dt}} & =\mathrm{C}(\theta v \mathrm{R}+\mathrm{Hz}-\mathrm{x}) \\
\frac{\mathrm{dH}}{\mathrm{dt}} & =\mathrm{H}(\rho w \mathrm{R}-\mathrm{y})
\end{aligned}
$$

Titik tetap $\left(\mathrm{R}^{*}, C^{*}, H^{*}\right)$ diperoleh dengan membuat $d R / d t=0, d C / d t=0, d H / d t=0$, sehingga menurut persamaan(4.1), (4.2), (4.3) diperoleh:

$$
\begin{aligned}
& R^{*}\left(u\left(1-\frac{R^{*}}{K}\right)-v C^{*}-w H^{*}\right)=0 \\
& C^{*}\left(\theta v R^{*}+H^{*} z-x\right)=0 \\
& H^{*}\left(\rho \mathrm{wR}{ }^{*}-y\right)=0
\end{aligned}
$$

Berikut ini akan ditentukan titik tetap $\left(R^{*}, C^{*}, H^{*}\right)$ yang memenuhi persamaan (4.1)-(4.3). Andaikan $R^{*}=0$, maka menurut persamaan $H^{*}\left(\rho w R^{*}-y\right)=0$ diperoleh $y=0$ (kontradiksi dengan asumsi y $>0$ ). Jadi haruslah $R^{*} \neq 0$. Berdasarkan uraian diatas, maka terdapat empat kasus:

1. $\left(u\left(1-\frac{R^{*}}{K}\right)-v C^{*}-w H^{*}\right)=0,\left(\theta v R^{*}+H^{*} z-x\right)=0, H^{*}=0$.

2. $\left(u\left(1-\frac{R^{*}}{K}\right)-v C^{*}-w H^{*}\right)=0, C^{*}=0,\left(\rho w R^{*}-y\right)=0$

3. $\left(u\left(1-\frac{R^{*}}{K}\right)-v C^{*}-w H^{*}\right)=0, C^{*}=0, H^{*}=0$.

4. $\left(u\left(1-\frac{R^{*}}{K}\right)-v C^{*}-w H^{*}\right)=0,\left(\theta v \mathrm{R}^{*}+H^{*} z-x\right)=0$ dan $\left(\rho w R^{*}-y\right)=0$

\section{Kasus 1:}

Dengan demikian titik tetap untuk kasus ini

$$
\left(u\left(1-\frac{R^{*}}{K}\right)-v C^{*}-w H^{*}\right)=0,\left(\theta v \mathrm{R}^{*}+H^{*} z-x\right)=0, H^{*}=0 T_{l}:\left(\frac{x}{\theta v}, \frac{u(K \theta v-x)}{\theta v^{2} K}, 0\right)
$$




\section{$\underline{\text { Kasus } 2}$}

$$
\left(u\left(1-\frac{R^{*}}{K}\right)-v C^{*}-w H^{*}\right)=O, C^{*}=0 \text { dan }\left(\rho \mathrm{wR}^{*}-y\right)=0
$$

Dengan demikian untuk titik tetap kasus ini adalah : $T_{2}:\left(\frac{y}{\rho w}, 0, \frac{u(K \rho w-y)}{\rho w^{2} K}\right)$

\section{Kasus 3:}

$$
\left(u\left(1-\frac{R^{*}}{K}\right)-v C^{*}-w H^{*}\right)=O, C^{*}=0 \text { dan } H^{*}=O
$$

Dengan demikian untuk titik tetap kasus ini adalah : $T_{3}:(K, 0,0)$

\section{$\underline{\text { Kasus } 4}$}

$$
\left(u\left(1-\frac{R^{*}}{K}\right)-v C^{*}-w H^{*}\right)=0,\left(\theta v \mathrm{R}^{*}+H^{*} z-x\right)=0 \text { dan }\left(\rho w R^{*}-y\right)=0
$$

Dengan demikian untuk titik tetap kasus ini adalah :

$$
T_{4}:\left(\frac{y}{\rho w}, \frac{1}{v}\left(\frac{u \rho w-u y}{\rho w K}-\frac{x \rho w-\theta v y}{\rho z}\right), \frac{x \rho w-\theta v y}{\rho w z}\right)
$$

\subsection{Konstruksi Matriks Jacobi}

Tulis persamaan (4.1), (4.2) dan (4.3) sebagai berikut :

$$
\begin{aligned}
& f(R, C, H)=R\left(u\left(1-\frac{R}{K}\right)-v C-w H\right) \\
& \mathrm{g}(\mathrm{R}, \mathrm{C}, \mathrm{H})=\mathrm{C}(\theta v R+H z-\mathrm{x}) \\
& \mathrm{j}(\mathrm{R}, \mathrm{C}, \mathrm{H})=\mathrm{H}(\rho w \mathrm{R}-\mathrm{y})
\end{aligned}
$$

Bentuk persamaan diferensial (4.1)-(4.3) dilinearkan dengan membentuk Matriks Jacobi sebagai berikut :

Dengan

$$
J=\left[\begin{array}{ccc}
\frac{\partial f(R, C, H)}{\partial R} & \frac{\partial f(R, C, H)}{\partial C} & \frac{\partial f(R, C, H)}{\partial H} \\
\frac{\partial g(R, C, H)}{\partial R} & \frac{\partial g(R, C, H)}{\partial C} & \frac{\partial g(R, C, H)}{\partial H} \\
\frac{\partial j(R, C, H)}{\partial R} & \frac{\partial j(R, C, H)}{\partial C} & \frac{\partial j(R, C, H)}{\partial H}
\end{array}\right]
$$

$$
\begin{aligned}
& f(R, C, H) \quad=R\left(u\left(1-\frac{R}{K}\right)-v C-w H\right) \\
& \frac{\partial f(R, C, H)}{\partial R} \quad=R\left(u\left(1-\frac{R}{K}\right)-v C-w H\right)=\left(\mathrm{u}-\frac{2 u R}{K}-v C-w H\right) \\
& f(\mathrm{R}, \mathrm{C}, \mathrm{H}) \quad=R\left(u\left(1-\frac{R}{K}\right)-v C-w H\right) \\
& \frac{\partial f(R, C, H)}{\partial C}=R\left(u\left(1-\frac{R}{K}\right)-v C-w H\right)=-v R
\end{aligned}
$$




$$
\begin{aligned}
& f(R, C, H) \quad=R\left(u\left(1-\frac{R}{K}\right)-v C-w H\right) \\
& \frac{\partial f(R, C, H)}{\partial H}=R u\left(1-\frac{R}{K}\right)-R v C-R w H=-R w \\
& g(R, C, H) \quad=C(\theta v R+H z-x) \\
& \frac{\partial g(R, C, H)}{\partial R}=C(\theta v R+H z-x)=C \theta v \\
& g(R, C, H)=C(\theta v R+H z-x) \\
& \frac{\partial g(R, C, H)}{\partial C}=C(\theta \nu R+H z-x)=\theta \nu R+H z-x \\
& g(R, C, H)=C(\theta v R+H z-x) \\
& \frac{\partial g(R, C, H)}{\partial H}=C(\theta v R+H z-x)=\mathrm{Cz} \\
& j(R, C, H) \quad=H(\rho w R-y)=H \rho w R-H \\
& \frac{\partial j(R, C, H)}{\partial R}=H \rho w R-H y=H \rho w \\
& \frac{\partial j(R, C, H)}{\partial C}=H(\rho w R-y) \quad=0 \\
& j(R, C, H) \quad=H(\rho w R-y) \\
& \frac{\partial j(R, C, H)}{\partial H}=H(\rho w R-y)=\rho w R-y
\end{aligned}
$$

maka matriks komunitas yang diperoleh dari system persamaan adalah:

$J=\left[\begin{array}{lll}a_{11} & a_{12} & a_{13} \\ a_{21} & a_{22} & a_{23} \\ a_{31} & a_{32} & a_{33}\end{array}\right]$

dengan $a_{11}, a_{12,}, \ldots a_{33}$ secara berturut - turut diberikan pada persamaan

Dari keempat kasus yang didapat ternyata pada kasus satu dan kasus empat tidak terdapat kestabilan, disebabkan karena pada masing-masing persamaan tidak memenuhi syarat kestabilan. Sedangkan pada kasus dua dan tiga terdapat kestabilan titik tetap $T_{2}$ untuk kasus $T_{2}$, dan titik tetap T3 untuk kasus T3. Jadi secara ekologi, kestabilan disekitar titik tetap $\mathrm{T}_{2}$ terjadi jika, penurunan tingkat pertumbuhan mangsa dengan tingkat kematian pemangsaan pemangsa harus kurang dari jumlah tingkat pertumbuhan mangsa dalam menggunakan daya dukung dengan efisiensi konversi tingkat pemangsaan pemangsa serta tingkat kematian pemangsa dengan tingkat pertumbuhan mangsa (untuk persamaan satu) dan dua kali keadaan daya dukung lingkungan dan efisiensi konversi tingkat pemangsaan pemangsa $H$ kurang dari jumlah tingkat kematian pemangsa $H$ dengan jumlah dari daya dukung lingkungan dan efisiensi konversi tingkat pemangsaan pemangsa $H$ (persamaan dua) demikian juga untuk persamaan yang ketiga.

Sedangkan untuk kestabilan disekitar titik tetap T3 akan terjadi jika, penjumlahan tingkat kematian pemangsa $C$ dengan tingkat pertumbuhan mangsa harus lebih besar dari efisiensi konversi tingkat pemangsaan pemangsa.

\section{Kesimpulan}

Kestabilan pada titik tetap $\mathrm{T}_{2}$ akan terjadi jika, penurunan tingkat pertumbuhan mangsa dengan tingkat kematian pemangsaan pemangsa harus kurang dari jumlah tingkat pertumbuhan 
mangsa dalam menggunakan daya dukung dengan efisiensi konversi tingkat pemangsaan pemangsa serta tingkat kematian pemangsa dengan tingkat pertumbuhan mangsa (untuk persamaan satu) dan dua kali keadaan daya dukung lingkungan dan efisiensi konversi tingkat pemangsaan pemangsa $H$ kurang dari jumlah tingkat kematian pemangsa $H$ dengan jumlah dari daya dukung lingkungan dan efisiensi konversi tingkat pemangsaan pemangsa $H$ (persamaan kedua dan tiga).

Kestabilan pada titik tetap T3 akan terjadi jika, penjumlahan tingkat kematian pemangsa $C$ dengan tingkat pertumbuhan mangsa harus lebih besar dari efisiensi konversi tingkat pemangsaan pemangsa $C$.

\section{Daftar Pustaka}

[1] Anton, H. 1991. Aljabar Linier Elementer. Edisi Kelima. Terjemahan Silaban, et al. Erlangga, Jakarta.

[2] Anonomius. Buku I Matematika dengan Matematica. FMIPA-IPB, Bogor.

[3] Anonomius. Buku II Matematika dengan Matematica. FMIPA-IPB, Bogor.

[4] Monareh K. D. 2007. Analisa Kestabilan Sistem Persamaan Diferensial dengan Menggunakan Prinsip Kestabilan Lin ieris asi [Skripsi]. FMIPA-UNSRAT, Manado.

[5] Edelstein dan Keshet, L. 1988. Mathematical Models in Biology. The Random House, New York.

[6] Fisher, S. D. 1990. Complex Variabels. $2^{\text {nd }}$ edition. Wadsworth \& Brooks/ColeBooks \& Software, Pacific Grove, California.

[7] Haberman, R.1961. Mathematical Models mechanical Vibrations, Populatio Dynamics, and Traffic Flow (An Introduction To Applied Mathematics). Department of Mathematics Rutgers University, New Jersey

[8] Hasibuan K. 1989. Bahan Pengajaran Pemodelan Matematika. Pusat Antar Universitas Ilmu Hayat Institut Pertanian Bogor, Bogor.

[9] http://mathworld.wolfram.com/Matriks Jacobian.html [25 February 2008].

[10] http://mathworld.wolfram.com/Turunan Parsial PartialDerivative.html[25 February].

[11] Mullen, A. J. 1984. Autonomic Tuning of a two Predator-One Prey System Via Commensalis m. Mathematical Biosciences 72:71-81.

[12] Manik, E. 2002. Himpunan dan Logika. FMIPA-UNSRAT, Manado.

[13] Purcell, J. E. 1994. Kalku lus dan Geometri Analisis. Edisi Keempat jilid 2. et all. Erlangga, Jakarta.

[14] Rindengan, A. 1999. Analisis Kestabilan Model Interaksi Dua Pemangsa-Satu Mangsa [ Skripsi]. FMIPA-IPB, Bogor.

[15] Taru mingkeng, R. C. 1994. Dinamika Populasi. Kajian Ekologi Kuantitatif. Pustaka Sinar Harapan, Jakarta. 